\title{
Survival of Normal and Chlorine-Stressed Pathogenic and Non-Pathogenic Vibrio parahaemolyticus Under Adverse Conditions
}

\author{
Mehdi Zarei $^{1, *}$; Mohammad Hadi Eskandari ${ }^{2}$; Somayeh Keshtkaran ${ }^{2}$ \\ ${ }^{1}$ Department of Food Hygiene, Faculty of Veterinary Medicine, Shahid Chamran University of Ahvaz, Ahvaz, IR Iran \\ ${ }^{2}$ Department of Food Science and Technology, College of Agriculture, Shiraz University, Shiraz, IR Iran \\ ${ }^{*}$ Corresponding author: Mehdi Zarei, Department of Food Hygiene, Faculty of Veterinary Medicine, Shahid Chamran University of Ahvaz, Ahvaz, IR Iran. Tel.: +98-9173021142; Fax: \\ +98-6113360807, E-mail: zarei@scu.ac.ir
}

Received: November 27, 2012; Revised: March 3, 2013; Accepted: March 17, 2013

\begin{abstract}
Background: Vibrio parahaemolyticus is an important human pathogen which can cause gastroenteritis when consumed in raw or partially-cooked seafood. The pathogenesis of V. parahaemolyticus is based on the presence of virulence factors: the thermostable direct hemolysin (TDH) and TDH-related hemolysin (TRH), encoded by the $t d h$ and trh genes, respectively.

Objectives: The present study aimed to evaluate the survival of normal and chlorine-stressed cells of pathogenic and non-pathogenic $V$. parahaemolyticus under adverse conditions.

Materials and Methods: Normal and chlorine-stressed cells of pathogenic and non-pathogenic V. parahaemolyticus were subjected to environmental stresses such as low storage temperature $\left(4^{\circ} \mathrm{C}\right.$ and $\left.-18^{\circ} \mathrm{C}\right)$, high incubation temperature $\left(50^{\circ} \mathrm{C}\right)$ and high $\mathrm{NaCl}$ content (20\%). Viable counts were then made at various time intervals by surface plating on TSA-2.0\% $\mathrm{NaCl}$, and the survival rates of the cells were determined and compared.

Results: Findings of the current study revealed that the normal cells of pathogenic and non-pathogenic V. parahaemolyticus, as well as the chlorine-stressed cells of both strains behave similarly under adverse conditions. In addition, chlorine stress increased the susceptibility of pathogenic and non-pathogenic $V$. parahaemolyticus to incubation at $4^{\circ} \mathrm{C}$, and the presence of high $\mathrm{NaCl}$ content in the medium. However, chlorine stress did not significantly affect the thermal tolerance of pathogenic and non-pathogenic V. parahaemolyticus, and the susceptibility to incubation at $-18^{\circ} \mathrm{C}$.

Conclusions: Chlorine-stressed cells of V. parahaemolyticus were more susceptible to adverse conditions than the non-stressed ones. Pathogenic and non-pathogenic strains showed the same survival characteristics under the adverse conditions. These results should be considered in the development of food preservation measures.
\end{abstract}

Keywords:Vibrio parahaemolyticus; Chlorine; Survival; Stress

\section{Background}

Vibrio parahaemolyticus is a Gram negative, halophilic bacterium recognized as an important food-borne pathogen worldwide. Consumption of raw or undercooked seafood, particularly shellfish, contaminated with V.parahaemolyticus may lead to development of acute gastroenteritis characterized by diarrhea, headache, vomiting, nausea, abdominal cramps and low fever $(1,2)$. Although the mechanism by which the organism infects humans has yet to be comprehensively determined, thermostable direct hemolysin (TDH) and TDH-related hemolysin (TRH) have been recognized as primary virulence factors in V. parahaemolyticus. The TDH and TRH hemolysins are produced by $V$. parahaemolyticus strains that respectively harbour $t d h$ and trh genes. It is commonly admitted that TDH is almost exclusively associated with clinical isolates, with less than $5 \%$ of environmental isolates producing TDH. As described with TDH and its gene, the frequency of trh-positive $V$. parahaemolyticus strains in the environment appears to be very low (3-5).

While preparing and processing food, microorganisms are commonly subjected to various stresses such as sanitizers, cold, heat, acid and preservatives. These stresses cause the injury or death of microorganisms and therefore are considered to hinder their proliferation resulting in longer and safer food preservation (6-8). Chlorine is the most widely used agent for disinfecting water which is usually added to water in the gaseous form, calcium, or sodium hypochlorite. Chlorination of the washing water is frequently used to reduce or remove microorganisms from the fishing vessels, surface of utensils, and equipment thus promoting a hygienic environment in food processing operations. Although chlorination is performed in order to kill the organisms, it is not always completely effective. Some organisms will only be injured by the chlorine and some will completely survive after the treatment. The process efficacy is influ- 
enced by dose, contact time, $\mathrm{pH}$ and presence of organic compounds (9).

We recently reported the seasonal prevalence of V.parahaemolyticus, including TDH-positive strains in shrimp samples in the South-western part of Iran (10). Since harvested shrimp in Iran, before packaging or processing, are washed with 2-7ppm chlorine containing water (11), $V$. parahaemolyticus is commonly exposed to chlorine. This exposure may induce some changes in the growth and survival characteristics of the remaining $V$. parahaemolyticus cells, regardless of the pathogenicity.

\section{Objectives}

The present study aimed to: (i) compare the survival of pathogenic and non-pathogenic V. parahaemolyticus under adverse conditions, (ii) investigate the effect of chlorine stress on the susceptibility of pathogenic and nonpathogenic $V$. parahaemolyticus to other environmental stresses, and (iii) compare the behavior of the chlorinestressed cells of pathogenic and non-pathogenic V. parahaemolyticus under adverse conditions.

\section{Materials and Methods}

\subsection{Microorganisms}

V. parahaemolyticus ( $t d h^{-}, t^{-} h^{-}$, Prince of Songkla University-PSU 2591) and V. parahaemolyticus ( $t d h^{+}$, trh', PSU 2551) were the organisms used in the current study. The test organisms were first activated by two successive transfers in Tryptic Soy Broth supplemented with $2 \% \mathrm{NaCl}$ at $35^{\circ} \mathrm{C}$ for $18-20 \mathrm{~h}$. This activated culture served as the inoculum.

\subsection{Preparation of the Chlorine Solutions and the Chlorine-Stressed Cells}

Chlorine solutions were made using calcium hypochlorite (Merck, Darmstadt, Germany) and sterile deionized water that had no chlorine demand. Total chlorine was determined according to ISO 7393-3:1990, using iodometric titration method (12).

To prepare the chlorine-stressed cells of pathogenic and non-pathogenic $V$. parahaemolyticus, first, the effect of chlorine concentration on the survival of pathogenic and non-pathogenic $V$. parahaemolyticus was investigated. Inoculum cultures of pathogenic and non-pathogenic $V$. parahaemolyticus $(1.0 \mathrm{~mL})$ were inoculated into $50 \mathrm{~mL}$ of deionized water-2.0\% $\mathrm{NaCl}$ (pH 7.5) containing $0.0,1.75,3.5$, and $7.0 \mathrm{ppm}$ chlorine at an initial population of $10^{6}-10^{7} \mathrm{cfu} / \mathrm{mL}$. They were all incubated at $35^{\circ} \mathrm{C}$ for a 5 $\mathrm{h}$ period. At different time intervals, the test organisms' survival was determined. Based on these results (data not shown), $3.5 \mathrm{ppm}$ chlorine was selected for preparation of the chlorine-stressed cells.

To achieve this goal, inoculum culture of $V$. parahaemolyticus $(1.0 \mathrm{~mL})$ was first harvested by centrifugation (10000 rpm, $5 \mathrm{~min}$ ) and washed with sterile deionized water-2.0\% $\mathrm{NaCl}(\mathrm{pH}=7.5)$ twice. They were then resuspended in $10.0 \mathrm{~mL}$ of the same water containing $3.5 \mathrm{ppm}$ chlorine and then held at room temperature for $30 \mathrm{~min}$. The cell suspension served as the source of chlorinestressed cells and was used in the experiments described in the present study. The control cells were also prepared by resuspension in sterile deionized water-2.0\% $\mathrm{NaCl}(\mathrm{pH}$ 7.5) at room temperature but they were not subjected to chlorine stress.

\subsection{The Effect of Chlorine Stress on the Survival of Pathogenic and Non-Pathogenic V.parahaemolyti- cus Under Adverse Conditions}

To determine the effect of chlorine stress on the survival of pathogenic and non-pathogenic V. parahaemolyticus at $4^{\circ} \mathrm{C}, 1.0 \mathrm{~mL}$ of the chlorine-stressed or control cells of pathogenic and non-pathogenic $V$. parahaemolyticus was inoculated into $50.0 \mathrm{~mL}$ of TSB-2.0\% $\mathrm{NaCl}$ (precooled at $4^{\circ} \mathrm{C}$ ) at an initial population of ca. $10^{6} \mathrm{cfu} /$ $\mathrm{mL}$ and incubated at $4^{\circ} \mathrm{C}$ for a 10 day period. Samples were taken at various time intervals to determine the cells' viability $(13,14)$. To investigate survival at $-18^{\circ} \mathrm{C}, 0.1$ $\mathrm{mL}$ of the chlorine-stressed or control cells of pathogenic and non-pathogenic V. parahaemolyticus was inoculated into each of the culture tubes containing 5.0 $\mathrm{mL}$ of the precooled TSB-2.0\% $\mathrm{NaCl}$ at an initial population of ca. $10^{6} \mathrm{cfu} / \mathrm{mL}$. Cells were then stored at $-18^{\circ} \mathrm{C}$ in a freezer for 7 days. At various storage times, tubes were removed from the freezer and contents were thawed at room temperature The viability of the cells was then determined $(13,14)$.

To determine the thermal tolerance of the test organisms, $1.0 \mathrm{~mL}$ of the chlorine-stressed cells or the control cells of pathogenic and non-pathogenic $V$. parahaemolyticus was inoculated into $50.0 \mathrm{~mL}$ TSB-2.0\% $\mathrm{NaCl}$ (pretempered at $50^{\circ} \mathrm{C}$ ) at an initial population of ca. $10^{6} \mathrm{cfu} / \mathrm{mL}$, and submerged in a preheated water bath at $50^{\circ} \mathrm{C}$ for 30 min. Samples were taken at different time intervals, and the survival of the cells was subsequently determined (13, 14). To examine susceptibility to high $\mathrm{NaCl}$ content, $1.0 \mathrm{~mL}$ of the chlorine-stressed cells or the control cells of pathogenic and non-pathogenic V. parahaemolyticus was inoculated into $50.0 \mathrm{~mL}$ of TSB containing $20 \% \mathrm{NaCl}$ at an initial population of ca. $10^{6} \mathrm{cfu} / \mathrm{mL}$. The cell suspensions were incubated at $35^{\circ} \mathrm{C}$ for a period of $6 \mathrm{~h}$ and the viability was determined after various durations of incubation $(13,14)$.

\subsection{Enumeration of V. parahaemolyticus}

To determine the viable population of $V$. parahaemolyticus, samples were first serially diluted with physiological saline solution. Viable counts were then made by surface plating $0.1 \mathrm{~mL}$ of the decimal diluted sample, each on duplicate plates of TSA-2.0\% NaCl. Colonies were counted after $24 \mathrm{~h}$ of incubation at $35^{\circ} \mathrm{C}(13,14)$. 
Zarei M et al.

\subsection{Statistical Analysis}

All experiments were performed in triplicate. SPSS software version 16 was employed to analyze the data through the Repeated Measure ANOVA and Independent Samples t test. The significance levels were expressed at a 95\% confidence level $(P \leq 0.05)$.

\section{Results}

\subsection{Survival of Pathogenic and Non-Pathogenic $V$. parahaemolyticus Under Adverse Conditions}

As shown in Figure $1 \mathrm{~A}-\mathrm{C}$, the survival rates of pathogenic and non-pathogenic V.parahaemolyticus decreased as the incubation time increased, in all the incubation temperatures tested. At the end of the incubation period at $50{ }^{\circ} \mathrm{C}$ (Figure $1 \mathrm{~A})$, pathogenic and non-pathogenic strains showed survival rates of ca. 1.1\% and, $2.4 \%$, respectively. When stored at low temperatures, viable populations of both strains showed a decreasing trend upon extending the storage time. At the end of the 10-day storage period at $4^{\circ} \mathrm{C}$, pathogenic and non-pathogenic strains showed survival rates of ca. 17.3\% and $12.5 \%$, respectively (Figure $1 \mathrm{~B}$ ). V. parahaemolyticus cells, regardless of their pathogenicity, declined to a greater extent at $-18^{\circ} \mathrm{C}$ (Figure $1 \mathrm{C}$ ) rather than at $4^{\circ} \mathrm{C}$. At the end of the 7-day storage period, pathogenic and non-pathogenic strains showed survival rates of ca. $0.04 \%$ and $0.02 \%$, respectively (Figure 1C). However, at the end of the incubation period, no significant difference was observed in the viable population of pathogenic and non-pathogenic strains in all the temperatures tested $(\mathrm{P}>0.05)$. The same result was observed in the presence of $20 \% \mathrm{NaCl}$ (Figure 1D), where at the end of the incubation time viable population of pathogenic $V$. parahaemolyticus decreased to $1.23 \%$, which did not differ significantly from that of the non-pathogenic strain (2.18\%).

\subsection{The Effect of Chlorine Stress on the Susceptibil- ity of Pathogenic and Non-Pathogenic V. parahae- molyticus to Various Environmental Stresses}

\subsubsection{The Effect of Chlorine Stress on the Survival at Low Temperatures}

As shown in Figure 2, the survival rates of chlorinestressed cells of pathogenic and non-pathogenic strains significantly decreased $(\mathrm{P}<0.05)$ compared to those of the control cells as the storage time at $4^{\circ} \mathrm{C}$ was extended. At the end of the 10-day storage, the control cells of pathogenic and non-pathogenic strains showed survival rates of $17.4 \%$ and $12.6 \%$, respectively. Meanwhile, chlorinestressed cells of both strains exhibited a significantly ( $\mathrm{P}$ $<0.05$ ) lower survival rates of $1.2 \%$ and $1.1 \%$, respectively. Comparing the behavior of chlorine-stressed cells of pathogenic and non-pathogenic $V$. parahaemolyticus dur- ing storage at $4^{\circ} \mathrm{C}$ showed no significant difference $(\mathrm{P}>$ 0.05), similar to the normal cells.

At $-18^{\circ} \mathrm{C}$, survival of both the control and chlorinestressed cells of pathogenic and non-pathogenic strains showed a decreasing trend upon extending the storage time (Figure 3). Although during the storage period, viable populations of the control cells of pathogenic and non-pathogenic strains were higher than those of the chlorine-stressed cells, they did not differ significantly $(\mathrm{P}>0.05)$. As observed at $4^{\circ} \mathrm{C}$, no significant difference was observed in the survival of chlorine-stressed cells of pathogenic and non-pathogenic $V$. parahaemolyticus during storage at $-18^{\circ} \mathrm{C}(\mathrm{P}>0.05)$.

Figure 1. Survival of Pathogenic ( $\mathbf{\square})$ and Non-Pathogenic $(\boldsymbol{\Delta})$ V. Parahaemolyticus at $50^{\circ} \mathrm{C}(\mathrm{A}), 4^{\circ} \mathrm{C}(\mathrm{B}),-18^{\circ} \mathrm{C}(\mathrm{C})$ and in the Presence of $20 \% \mathrm{NaCl}$ (D)
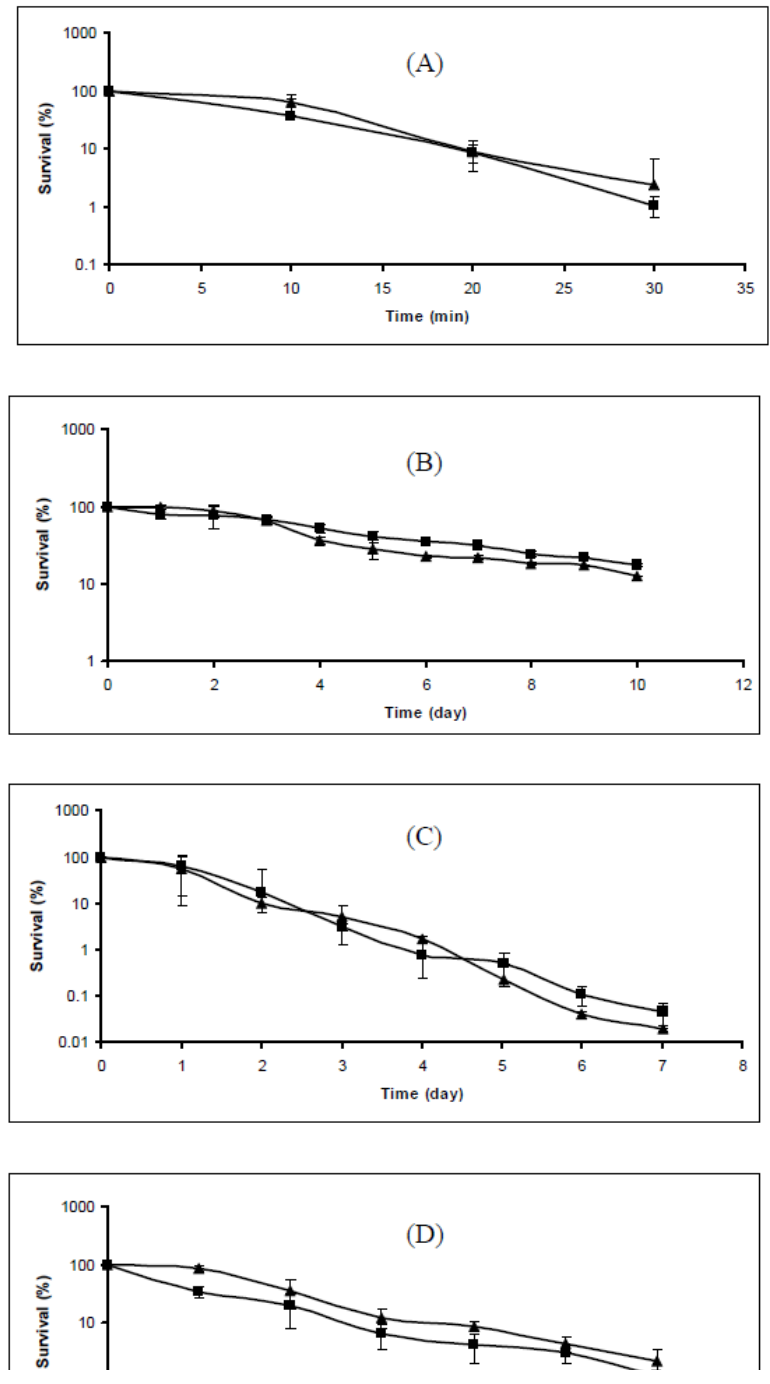

The initial populations were $10^{4}-10^{5} \mathrm{cfu} / \mathrm{mL}$. Survival rates were obtained by dividing the survival populations by the initial populations which corresponds to $100 \%$. 
Figure 2. Survival of Pathogenic (A) and Non-Pathogenic (B) V. Parahaemolyticus at $4^{\circ} \mathrm{C}$ : Control Cells ( $\left.\mathbf{\Delta}\right)$; Chlorine-Stressed Cells ( $\left.\mathbf{\square}\right)$

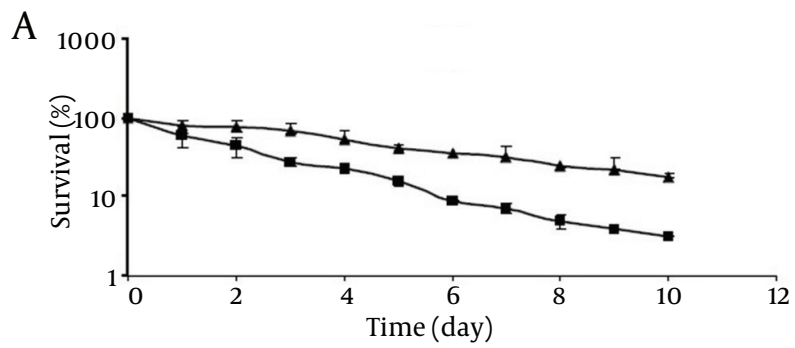

B

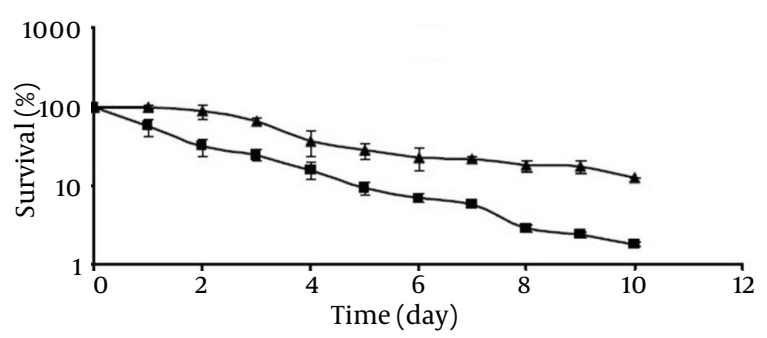

The initial populations were $10^{4}-10^{5} \mathrm{cfu} / \mathrm{mL}$. Survival rates were obtained by dividing the survival populations by the initial populations which corresponds to $100 \%$

Figure 3. Survival of Pathogenic (A) and Non-Pathogenic (B) V. Parahaemolyticus at $-18^{\circ} \mathrm{C}$ : Control Cells ( $\left.\boldsymbol{\Delta}\right)$; Chlorine-Stressed Cells ( $(\boldsymbol{\bullet})$

A

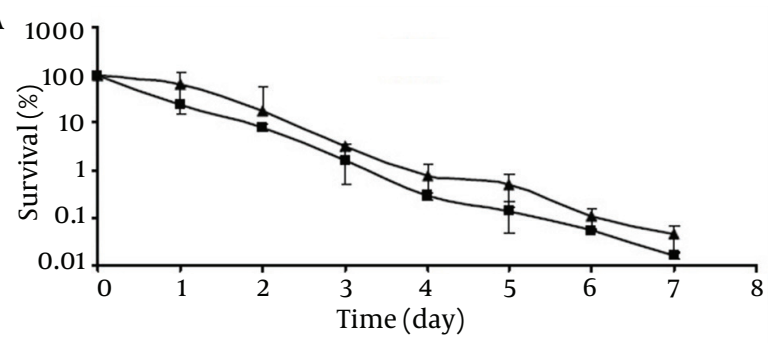

B

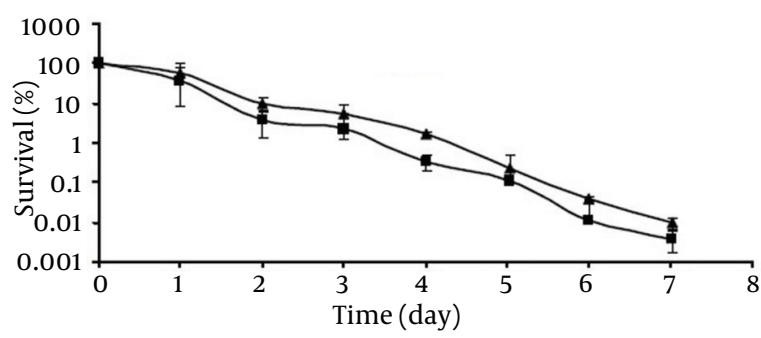

The initial populations were $10^{4}-10^{5} \mathrm{cfu} / \mathrm{mL}$. Survival rates were obtained by dividing the survival populations by the initial populations which corresponds to $100 \%$.
Figure 4. Survival of Pathogenic (A) and Non-Pathogenic (B) V. Parahaemolyticus at $50^{\circ} \mathrm{C}$ : Control Cells ( $\left.\mathbf{\Delta}\right)$; Chlorine-Stressed Cells ( $\left.\mathbf{\square}\right)$. The Initial Populations Were $10^{4}-10^{5} \mathrm{cfu} / \mathrm{mL}$

A

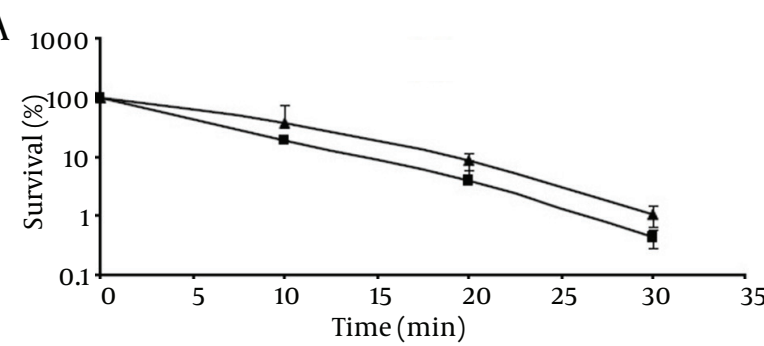

B

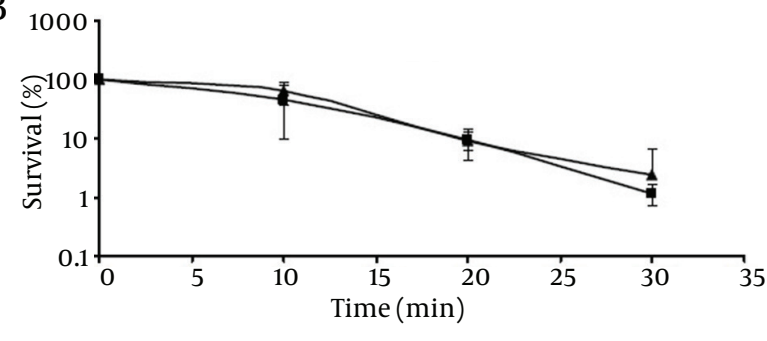

Survival rates were obtained by dividing the survival populations by the initial populations which corresponds to $100 \%$.

\subsubsection{The Effect of Chlorine Stress on the Thermal Toler- ance}

As shown in Figure 4, viability of both the control and chlorine-stressed cells, regardless of their pathogenicity, decreased as the incubation time at $50^{\circ} \mathrm{C}$ increased. At the end of the incubation period, control cells of pathogenic and non-pathogenic strains showed survival rates of ca. $1.1 \%$ and $2.4 \%$, respectively, which did not differ significantly $(P>0.05)$ from those observed with chlorinestressed cells of both strains ( $0.4 \%$ and $1.4 \%$ for pathogenic and non-pathogenic strains, respectively). Similar to the normal cells, comparing the survival of chlorine-stressed cells of pathogenic and non-pathogenic $V$. parahaemolyticus showed no significant difference $(\mathrm{P}>0.05)$.

\subsubsection{Effect of Chlorine Stress on the Susceptibility to High $\mathrm{NaCl}$ Content}

As shown in Figure 5, the survival rate of the chlorine stressed cells significantly decreased $(\mathrm{P}<0.05)$ compared to those of the control cells as the incubation time was extended. At the end of 6-hour incubation, control cells of pathogenic and non-pathogenic strains showed survival rates of $19.3 \%$ and $14.5 \%$, respectively. Meanwhile, chlorinestressed cells of both strains exhibited significantly $(\mathrm{P}<$ 0.05 ) lower survival rates of $5.6 \%$ and $4.0 \%$, respectively. In addition, comparing the survival rates of chlorinestressed cells of pathogenic and non-pathogenic V. parahaemolyticus showed no significant difference $(\mathrm{P}>0.05)$, similar to the normal cells. 
Figure 5. Survival of Pathogenic (A) and Non-Pathogenic (B) V. parahaemolyticus After Exposure to TSB Containing 20\% NaCl: Control Cells ( $\Delta$ ); Chlorine-Stressed Cells ( $\mathbf{\square})$

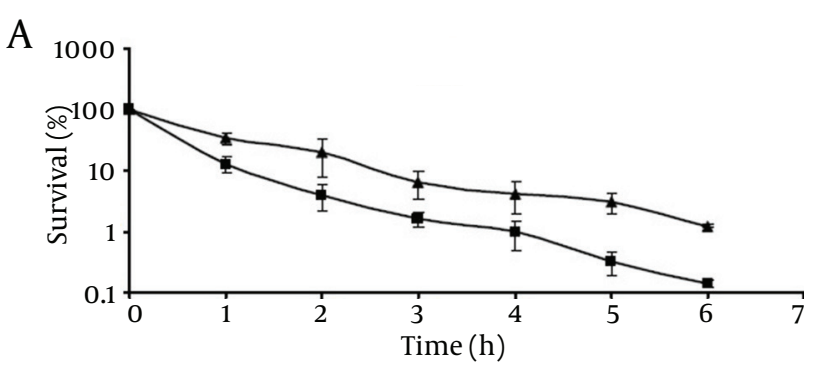

B

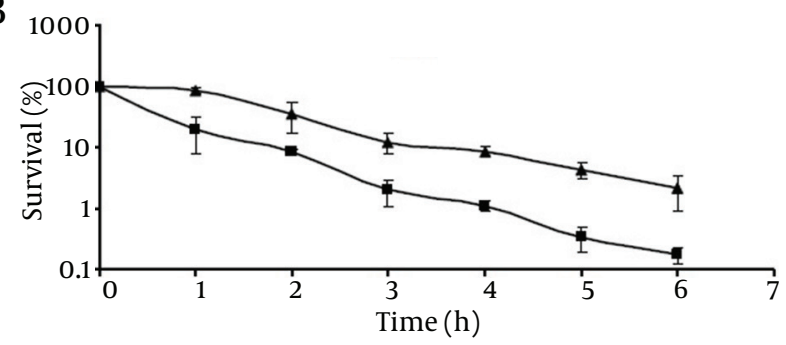

The initial populations were $10^{4}-10^{5} \mathrm{cfu} / \mathrm{mL}$. Survival rates were obtained by dividing the survival populations by the initial populations which corresponds to $100 \%$.

\section{Discussion}

The present study first compared the survival of normal cells of pathogenic and non-pathogenic V. parahaemolyticus under adverse conditions. According to the obtained results, although the survival rates of pathogenic and non-pathogenic strains decreased as the incubation time at $50^{\circ} \mathrm{C}$ increased (Figure $1 \mathrm{~A}$ ), no significant difference was observed. Besides, viable population of pathogenic and non-pathogenic $V$. parahaemolyticus decreased $(\mathrm{P}>0.05)$ at low temperatures, especially at $-18^{\circ} \mathrm{C}$ (Figure $1 \mathrm{~B}$ and $1 \mathrm{C}$ ). This is thought to be due to the entrance of $V$. parahaemolyticus into a viable but nonculturable (VBNC) state. It has been previously demonstrated that this inability to culture certain Vibrio species from low-temperature environments is not due to the cell death, but to the viable but nonculturable state, which defines the inability of cells to produce colonies on appropriate solid media even following prolonged incubation (15).

To evaluate the effect of chlorine stress on the susceptibility of pathogenic and non-pathogenic $V$. parahaemolyticus to various environmental stresses, the current study demonstrated that chlorine stress made $V$. parahaemolyticus cells, more susceptible to incubation at $4{ }^{\circ} \mathrm{C}$, regardless of their pathogenicity, The higher susceptibility of chlorine-stressed cells to low storage temperature could be due to the injuries caused by chlorine in viable population of $V$. parahaemolyticus. When chlorine gas or aqueous solutions of calcium and sodium hypochlorite is added to water, a reaction occurs splitting it into hypo- chlorous acid and hypochlorite ions. The hypochlorous acid is the active killing form of chlorine. This chlorine molecule easily enters microorganisms through their cell walls and kills the organisms by destroying the sulfur groups on the cells' enzymes, causing cells to stop metabolism, and resulting in the cell death. The amount of hypochlorous acid and hypochlorite ion produced following chlorine addition to water is directly related to the $\mathrm{pH}$ of the water. At a pH of 7.5 (the current study) the amount of hypochlorous acid produced was about 50\% (3). Chlorine, at low level, is only lethal for a small number of exposed cells but induces injury in a large proportion of the remaining bacterial population (9). According to the previous reports, cold shock resulted in an enhanced resistance of $V$. parahaemolyticus (14) and ethanol shock induced no significant alteration in survival of V.parahaemolyticus at $4^{\circ} \mathrm{C}(13)$.

However, chlorine stress did not significantly alter the survival of pathogenic and non-pathogenic $V$. parahaemolyticus at $-18^{\circ} \mathrm{C}$. This may be due to the entrance of a large population of pathogenic and non-pathogenic $V$. parahaemolyticus, regardless of the chlorine stress, into a viable but nonculturable state following the incubation at freezing temperature. In addition, formation of ice crystals and solute concentration effect, which occurs at freezing temperature, are detrimental to microorganisms (16). Contrary to the results of the current study, enhanced susceptibility of $V$. parahaemolyticus at $-18^{\circ} \mathrm{C}$ after ethanol shock treatment had been previously reported (13).

Although ethanol shock resulted in an enhanced resistance of V.parahaemolyticus (13), and cold shock made the cells more susceptible to high temperature (13), chlorine stress induced no significant alteration $(P>0.05)$ in the survival of pathogenic and non-pathogenic $V$. parahaemolyticus at $50^{\circ} \mathrm{C}$. High concentrations of $\mathrm{NaCl}$ may lead to plasmolysis, injury and death of microorganisms (17). Therefore, in addition to impart salty flavor, $\mathrm{NaCl}$ is commonly used in various steps of food preparation to inhibit the growth of spoilage and pathogenic bacteria. It has been previously reported that environmental stress might affect the susceptibility of microorganism to high salt content. For example, V. parahaemolyticus became more susceptible to high $\mathrm{NaCl}$ content after exposure to ethanol shock (2) or heat shock treatments (18). In the present study, chlorine stress was also found to enhance the susceptibility of pathogenic and non-pathogenic $V$. parahaemolyticus to high $\mathrm{NaCl}(\mathrm{P}<0.05)$.

The results of the present study demonstrated that pathogenic and non-pathogenic V. parahaemolyticus had the same survival characteristics under adverse conditions. They also behaved similarly after chlorine stress. Moreover, chlorine stress increased the susceptibility of pathogenic and non-pathogenic $V$. parahaemolyticus to incubation at $4^{\circ} \mathrm{C}$ and the presence of high $\mathrm{NaCl}$ content in the medium. However, chlorine stress neither significantly alter the thermal tolerance of pathogenic and non- 
pathogenic $V$. parahaemolyticus, nor the susceptibility to freezing temperature. These results should be considered in the development of food preservation measures.

\section{Acknowledgements}

The authors would like to thank Mrs. Parisa Esfahani for her kind assistance.

\section{Authors' Contribution}

Mehdi Zarei and Mahammad Hadi Eskandari developed the original idea and the protocol. Somayeh Keshtkaran contributed to the experimental work.

\section{Financial Disclosure}

There is no financial disclosure.

\section{Funding/Support}

This study was supported by the research grants provided by Shiraz University and Shahid Chamran University of Ahvaz.

\section{References}

1. Cho SH, Shin HH, Choi YH, Park MS, Lee BK. Enteric bacteria isolated from acute diarrheal patients in the Republic of Korea between the year 2004 and 2006. J Microbiol. 2008;46(3):325-30.

2. Sakazaki R. Vibrio. In: Cliver DO, Riemann H editors. Foodborne Diseases.. US: Academic Press; 2002. pp. 127-36.

3. Hervio-Heath D, Colwell RR, Derrien A, Robert-Pillot A, Fournier JM, Pommepuy M. Occurrence of pathogenic vibrios in coastal areas of France. J Appl Microbiol. 2002;92(6):1123-35.

4. Martinez-Urtaza J, Lozano-Leon A, Varela-Pet J, Trinanes J, Pazos Y, Garcia-Martin O.Environmental determinants of the occurrence and distribution of Vibrio parahaemolyticus in the rias of Galicia, Spain. Appl Environ Microbiol. 2008;74(1):265-74.
5. Wong HC, Liu SH, Ku LW, Lee IY, Wang TK, Lee YS, et al. Characterization of Vibrio parahaemolyticus isolates obtained from foodborne illness outbreaks during 1992 through 1995 in Taiwan. J Food Prot. 2000;63(7):900-6.

6. Browne N, Dowds BC. Acid stress in the food pathogen Bacillus cereus. J Appl Microbiol. 2002;92(3):404-14.

7. Chiang ML, Ho WL, Chou CC. Ethanol shock changes the fatty acid profile and survival behavior of Vibrio parahaemolyticus in various stress conditions. Food Microbiol. 2008;25(2):359-65.

8. Lou Y, Yousef AE. Adaptation to sublethal environmental stresses protects Listeria monocytogenes against lethal preservation factors. Appl Environ Microbiol. 1997;63(4):1252-5.

9. Sampognaro G, Turgut T, Conners JJ, 3rd, White C, Collins T, Ramee SR. Intra-arterial thrombolysis in a patient presenting with an ischemic stroke due to spontaneous internal carotid artery dissection. Catheter Cardiovasc Interv. 1999;48(3):312-5.

10. Zarei M, Pourmahdi Borujeni M, Jamnejad A, Khezrzadeh M. Seasonal prevalence of Vibrio species in retail shrimps with an emphasis on Vibrio parahaemolyticus. Food Control. 2012;25(1):107-9.

11. Rahimi E, Ameri M, Doosti A, Gholampour AR. Occurrence of toxigenic Vibrio parahaemolyticus strains in shrimp in Iran. Foodborne Pathog Dis. 2010;7(9):1107-11.

12. International Standard. Water quality - Determination of free chlorine and total chlorine-Part 3: Iodometric titration method for the determination of total chlorine. 1990. Available from: http://www.saiglobal.com/ pdftemp/previews/osh/iso/ipdfo040/t014108e.pdf.

13. Chiang ML, Ho WL, Chou CC. Response of Vibrio parahaemolyti cus to ethanol shock. Food Microbiol. 2006;23(5):461-7.

14. Lin C, Yu RC, Chou CC. Susceptibility of Vibrio parahaemolyticus to various environmental stresses after cold shock treatment. Int JFood Microbiol. 2004;92(2):207-15.

15. Jiang X, Chai TJ. Survival of Vibrio parahaemolyticus at low temperatures under starvation conditions and subsequent resuscitation of viable, nonculturable cells. Appl Environ Microbiol. 1996;62(4):1300-5.

16. Davies R, Obafemi A. Response of micro-organism to freeze-thaw stress. In: Robinson RK editor. Microbiology of Frozen Foods.; 1985. pp. 83-107.

17. Jay JM. Modern Food Microbiology. 6 edSingapore: Aspen Publishers; 2000.

18. Chiang ML, Yu RC, Chou CC. Fatty acid composition, cell morphology and responses to challenge by organic acid and sodium chloride of heat-shocked Vibrio parahaemolyticus. Int J Food Microbiol. 2005;104(2):179-87. 